\title{
ECONOMETRIC TESTS OF ASSET PRICE BUBBLES: TAKING STOCK*
}

\author{
Refet S. Gürkaynak \\ Bilkent University
}

\begin{abstract}
Can asset price bubbles be detected? This survey of econometric tests of asset price bubbles shows that, despite recent advances, econometric detection of asset price bubbles cannot be achieved with a satisfactory degree of certainty. For each paper that finds evidence of bubbles, there is another one that fits the data equally well without allowing for a bubble. We are still unable to distinguish bubbles from time-varying or regime-switching fundamentals, while many small sample econometrics problems of bubble tests remain unresolved.
\end{abstract}

Keywords. Bubbles; Econometric tests; Identification

\section{Introduction}

Figure 1 shows the real S\&P500 stock price index from 1871 to 2003, using annual data. ${ }^{1}$ The run up in equity prices in the late 1990 s seems extraordinary, especially given the ensuing decline. Similar boom-bust episodes in US stock prices were also seen in 1929 and 1987 (see Shiller, 2000; Miskin and White, 2002, for historical accounts of stock market booms and crashes). Many casual commentators attributed this steep rise in stock prices to the presence of a bubble. Can such a claim be substantiated using econometric methods?

A large and growing number of papers propose methods to detect 'rational' bubbles. Equity prices contain a rational bubble if investors are willing to pay more for the stock than they know is justified by the value of the discounted dividend stream because they expect to be able to sell it at an even higher price in the future, making the current high price an equilibrium price. Importantly, the pricing of the equity is still rational, and there are no arbitrage opportunities when there are rational bubbles. Section 2 below develops the basic asset pricing relation and rational bubbles from a utility maximization problem and points out the assumptions embedded in the 'standard' model.

Testing for bubbles, as will be seen below, is essentially testing the validity of the standard model, observing either whether it fails at all, or whether it fails in a way that can be attributed to bubbles. There is an extensive literature on the econometric tests of bubbles and it is not always easy to have a holistic sense of where this literature stands. This paper helps making sense of the literature easier

*I thank Jim Clouse, Bill Nelson, Brian Sack and Jonathan Wright for helpful suggestions.

Journal of Economic Surveys (2008) Vol. 22, No. 1, pp. 166-186

(C) 2008 The Author. Journal compilation (C) 2008 Blackwell Publishing Ltd, 9600 Garsington Road, Oxford OX4 2DQ, UK and 350 Main Street, Malden, MA 02148, USA. 


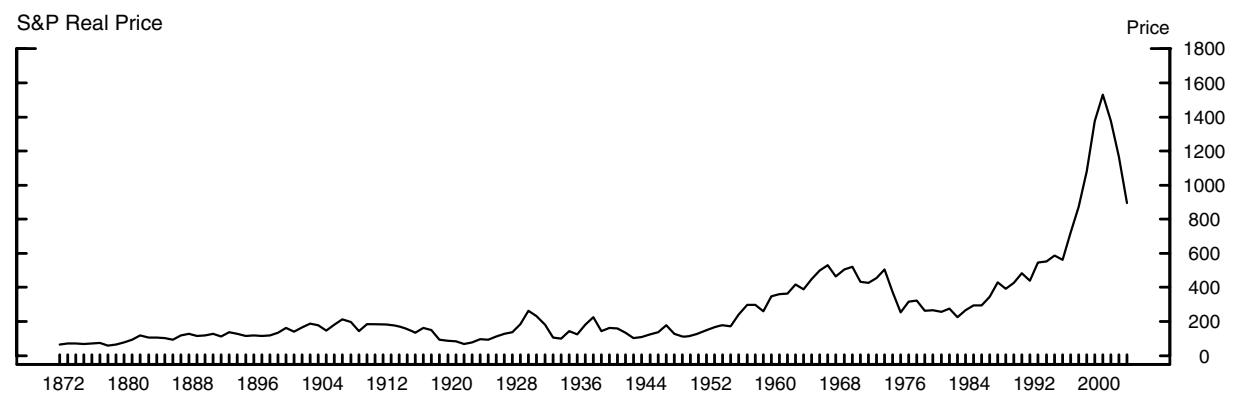

Figure 1. S\&P Real Price, 1871-2003.

by presenting a survey of the tests and their criticisms from within the same basic framework.

Section 3 is the main body of the paper and surveys the literature on testing for rational bubbles in the context of the present value of dividends model (see West, 1988b; Camerer, 1989, for surveys of the earlier literature). Importantly, this is a survey of the methods, not a survey of applications; thus the emphasis is on the econometric methods proposed for bubble detection and their critiques, rather than the sample periods used in applications or the particular results obtained. The survey begins with the variance bounds tests (Section 3.1) of Shiller (1981) and LeRoy and Porter (1981), which were not designed as bubble tests but were later used in that fashion. West's tests of bubbles $(1987,1988$ a) are taken up in Section 3.2. Section 3.3 focuses on the integration/cointegration based tests (Diba and Grossman, 1988a, b) and Evans's (1991) criticism of this approach. Tests of collapsing bubbles are also introduced in this section. Section 3.4 discusses intrinsic bubbles, their econometric detection, and related models of regime-switching fundamentals.

The bottom line is that available econometric tests are not that effective because they combine the null hypothesis of no bubbles with an overly simple model of fundamentals. Thus, rejections of the present value model that are interpreted by some as indicating the presence of bubbles can still be explained by alternative structures for the fundamentals. This is not only a theoretical possibility; for almost every paper in the literature that 'finds' a bubble, there is another one that relaxes some assumption on the fundamentals and fits the data equally well without resorting to a bubble.

All of the papers surveyed in this paper are tests of rational bubbles, as explained below. A more recent, alternative strand of literature uses behavioural models that allow for irrational pricing and associated 'irrational bubbles'. These models, and their tests, are not covered in this paper; readers interested in this strand of literature are referred to Vissing-Jorgensen (2004) for a survey.

Most of the tests surveyed below reject the standard model of stock pricing. Although they do not reject the null in a way that is consistent only with a bubble, these tests do provide valuable information about the particular dimensions of the 
standard, present discounted value of dividends model that are inconsistent with the data. The best tests can show whether the data are inconsistent with the presence of a bubble, but there are no tests that would show the data are only consistent with a bubble and not with at least equally plausible alternatives.

\section{Asset Prices and Bubbles}

Consumers' optimization problem can be used to derive the basic asset pricing relationship assuming no arbitrage and rational expectations - standard assumptions in economics and finance. For simplicity let expected utility driven from consumption, $u(c)$, be maximized in an endowment economy,

$$
\operatorname{Max} E_{t}\left\{\sum_{i=0}^{\infty} \beta^{i} u\left(c_{t+i}\right)\right\}
$$

subject to

$$
c_{t+i}=y_{t+i}+\left(P_{t+i}+d_{t+i}\right) x_{t+i}-P_{t+i} x_{t+i+1}
$$

where $y_{t}$ is the endowment, $\beta$ is the discount rate of future consumption, $x_{t}$ is the storable asset, $P_{t}$ is the after-dividend price of the asset and $d_{t}$ is the payoff (dividend) received from the asset. In this paper the focus is on stock prices and thus $P_{t}$ is a stock price and $d_{t}$ is dividend; however, in different contexts $P_{t}$ may be a house price and $d_{t}$ rent, or $P_{t}$ may be price of a mine and $d_{t}$ the value of ore unearthed every period.

The optimization problem's first order condition is

$$
E_{t}\left\{\beta u^{\prime}\left(c_{t+i}\right)\left[P_{t+i}+d_{t+i}\right]\right\}=E_{t}\left\{u^{\prime}\left(c_{t+i-1}\right) P_{t+i-1}\right\}
$$

For asset pricing purposes, it is often implicitly or explicitly assumed that utility is linear, which implies constant marginal utility and risk neutrality. In this case, equation (1) simplifies to

$$
\beta E_{t}\left(P_{t+i}+d_{t+i}\right)=E_{t}\left(P_{t+i-1}\right)
$$

Assuming further the existence of a riskless bond available in zero net supply with one period net interest rate, $r$, no arbitrage implies

$$
E_{t}\left(P_{t+i-1}\right)=\frac{1}{1+r} E_{t}\left(P_{t+i}+d_{t+i}\right)
$$

Equation (2) is the starting point of most empirical asset pricing tests. This firstdegree difference equation can be iterated forward to reveal the solution

$$
P_{t}=\sum_{i=1}^{\infty}\left(\frac{1}{1+r}\right)^{i} E_{t}\left(d_{t+i}\right)+B_{t}
$$

such that

$$
E_{t}\left(B_{t+1}\right)=(1+r) B_{t}
$$


The asset price has two components, a 'market fundamental' part, which is the discounted value of expected future dividends, the first term on the right-hand side of equation (3), and a 'bubble' part, the second term. In this setup, the rational bubble is not a mispricing effect but a basic component of the asset price. Despite the potential presence of a bubble, there are no arbitrage opportunities - equation (4) rules these out.

Under the assumption that dividends grow slower than $r$, the market fundamental part of the asset price converges. The bubble part, in contrast, is non-stationary. ${ }^{2}$ The price of the asset may exceed its fundamental value as long as agents expect that they can sell the asset at an even higher price at a future date. Notice that the expectation of making high capital gains from the sale of the asset in the future is consistent with no-arbitrage pricing as the value of the right to sell the asset is priced in. Importantly, the path of the bubble (and consequently the asset price) is not unique. Equation (4) only restricts the law of motion of the non-fundamental part of the asset price, but it implies a different path for each possible value of the initial level of the bubble. An additional assumption about $B_{t}$ is required to determine the asset price.

A special case of the solution that pins down the asset price is $B_{t}=0$, which implies that the value of the bubble is zero at all times. This is the fundamental solution that forms the basis of present value pricing approaches to equity prices. In the remainder of the paper this solution is alternatively called 'the standard model', 'the present value model' and 'the market fundamentals model'.

It is useful to explicitly spell out the assumptions other than the absence of bubbles that are embedded in this formulation of the present value pricing model.

1. There are no informational asymmetries. Price movements are not amplified (or driven) by uninformed (e.g. momentum) traders who try to extract information from prices.

2. The representative consumer is risk neutral. A corollary of this assumption is that there are no risk premia. This, obviously, rules out time-varying risk premia due to variation in the price or amount of risk as an explanation of volatility of stock prices.

3. The discount rate is constant. Note that this is a restriction on $r$, rather than on $\beta$, although they are not really differentiated in this model. If the discount rate is constant at $r$ and dividends grow at the constant rate $g, r$ must be greater than $g$ for the sum of the discounted dividend stream to be finite.

4. The process that generates dividends is not expected to change. Although this is not an assumption about the model per se, it is an assumption commonly made in the econometric tests of this model. Many econometric tests need to generate an estimate of expected dividends based on history. This exercise is meaningful only if the dividend generating process is not expected to change in the future.

As stated above, the market fundamentals model is a special case of a more general model that allows for bubbles. The no bubbles special case is justified by a transversality condition in infinite horizon models. The price of the asset today 
is the sum of the net present value of expected dividends and the expected resale value:

$$
P_{t}=\sum_{i=1}^{\infty}\left(\frac{1}{1+r}\right)^{i} E_{t}\left(d_{t+i}\right)+\lim _{i \rightarrow \infty}\left(\frac{1}{1+r}\right)^{i} P_{t+i}
$$

The transversality condition asserts that the second term on the right-hand side is zero. This is justified by the following argument. If there is a positive bubble and this term is not zero, the infinitely lived agent could sell the asset and the lost utility, which is the discounted value of the dividend stream, will be lower than the sale value. This cannot be an equilibrium price as all agents will want to sell the asset and the price will fall to the fundamental level. Tirole (1982) argues that bubbles can be ruled out in infinitely lived rational expectations models, but the same author (1985) shows that bubble paths for asset prices are possible in overlapping generations models.

The current literature usually takes it as given that non-fundamentals based asset prices are possible, skipping the theoretical existence problem and treating bubbles as an empirical issue. The empirical tests usually start from equations (3) and (4), without delving into general equilibrium arguments.

\section{Econometric Tests of Rational Bubbles}

\subsection{Variance Bounds Tests}

Variance bounds tests for equity prices were initiated by Shiller (1981) and LeRoy and Porter (1981). Shiller's test only generates point estimates of variances so statistical significance cannot be tested, whereas LeRoy and Porter treat equity prices and dividends as a bivariate process, constructing estimates of variances with standard errors. ${ }^{3}$ Here we follow Shiller for ease of exposition. ${ }^{4}$

The null hypothesis is that the 'market fundamental' solution to equation (3) forms the basis of asset prices, so that

$$
P_{t}=\sum_{i=1}^{\infty}\left(\frac{1}{1+r}\right)^{i} E_{t}\left(d_{t+i}\right)
$$

Then $P^{*}$, the ex post rational price, can be defined as the present value of actual (as opposed to expected) dividends:

$$
P_{t}^{*}=\sum_{i=1}^{\infty}\left(\frac{1}{1+r}\right)^{i} d_{t+i}
$$

Under rational expectations the difference between actual and expected dividends is an unforecastable, mean zero variable. Denoting this difference by $\varepsilon_{t}$,

$$
P_{t}^{*}=\sum_{i=1}^{\infty}\left(\frac{1}{1+r}\right)^{i}\left[E_{t}\left(d_{t+i}\right)+\varepsilon_{i}\right]=P_{t}+\sum_{i=1}^{\infty}\left(\frac{1}{1+r}\right)^{i} \varepsilon_{t+i}
$$


The variance bounds tests rest on the observation that, as $\varepsilon_{t}$ is uncorrelated with all information at time $t$, including $P_{t}$, the variance of $P_{t}^{*}$ can be written as

$$
V\left(P_{t}^{*}\right)=V\left(P_{t}\right)+\varphi V\left(\varepsilon_{t}\right) \geq V\left(P_{t}\right)
$$

where $\varphi$ is $[1 /(1+r)]^{2} /\left[1-(1 /(1+r))^{2}\right]$. Equation (7) places an upper bound on the variance of the observed price series, under the assumption that prices are formed according to (5). The ex post rational price should be at least as variable as the observed prices because observed prices are based on expected dividends and do not have the variation introduced by future forecast errors, which the ex post price includes. If the variance bound is violated in data, this will be evidence that equity prices do not follow equation (5).

The implementation of the variance bound test is more complicated than its theory because $P_{t}^{*}$ is never observed as the values of $d_{t}$ out to infinity are unrealized. For empirical applications it is approximated by assuming a terminal value of $P_{T}^{*}$, where $T$ is today, the last data point, and constructing the $P^{*}$ series recursively using observed values of dividends. For the terminal price Shiller (1981) uses the sample average of detrended real price.

Shiller's test shows that actual price volatility exceeds the bound imposed by the variance of ex post rational price by an order of magnitude. ${ }^{5}$ Although Shiller (1981) and Grossman and Shiller (1981) used this evidence as a critique of the present value model in general, without attributing the high volatility of equity prices to bubbles, other authors, including Tirole (1985) and Blanchard and Watson (1982), have suggested that the variance bound may be violated due to the presence of bubbles.

Although a violation of the variance bound, constructed as above, might be due to the presence of bubbles, these tests have problems with implementation that makes them unsuitable for bubble detection. Some of these are broad problems that are present when variance bounds tests are used to evaluate the present value model, and are not specific to testing for bubbles. Flavin (1983) has shown that using the mean price as the terminal ex post rational price biases the test towards rejection in small samples. Kleidon (1986) argues a subtler point: the variances in question, theoretically, are cross-section variances at a point in time, but in estimation timeseries variances are used. He shows that data constructed from the net present value model violate the variance bound when non-stationary time-series variances are used. Marsh and Merton (1983) also provide a striking example of variance bounds tests failing when dividends and stock prices are non-stationary. In more recent work on the topic, using simulated data, Akdeniz et al. (2006) argue that variance bounds should not be used for inference on market efficiency.

These criticisms apply to the use of variance bounds tests to refute the present value model. To get around the Flavin criticism, the test has been modified to use the last observed price as the terminal price, which indeed makes the actual price the expected value of the ex post rational price. This approach has a problem that is specific to bubble detection. Authors as early as Mankiw et al. (1985), ${ }^{6}$ who employed this method, have noted that in this case variance bounds tests are not well suited for bubble detection, as explained below. 
This terminal value assumption defines the observable counterpart of the ex post rational price as

$$
\tilde{P}_{t}=\sum_{i=t+1}^{T}\left(\frac{1}{1+r}\right)^{i-t} d_{i}+\left(\frac{1}{1+r}\right)^{T-t} P_{T}
$$

Under the null hypothesis that there are no bubbles present, this adds some noise to the ex post rational price, but does not reverse the variance bound inequality. The important point is that, under the assumption that there is a rational bubble in the data, the variance bound still stands, i.e. this is not a test of bubbles (Flood et al., 1994). To see this, assume that

$$
P_{t}=\sum_{i=1}^{\infty}\left(\frac{1}{1+r}\right)^{i} E_{t}\left(d_{t+i}\right)+B_{t}
$$

as in equation (3), and $B_{t} \neq 0$. Then, with some algebra, $\tilde{P}_{t}$ can be written as

$$
\begin{aligned}
\tilde{P}_{t}= & P_{t}+\sum_{i=t+1}^{T}\left(\frac{1}{1+r}\right)^{i-t} \varepsilon_{i} \\
& +\sum_{i=T+1}^{\infty}\left(\frac{1}{1+r}\right)^{i-t}\left[E_{T}\left(d_{i}\right)-E_{t}\left(d_{i}\right)\right]+\left[\left(\frac{1}{1+r}\right)^{T-t} B_{T}-B_{t}\right]
\end{aligned}
$$

The last three terms on the right-hand side are forecast errors or forecast updates and are all uncorrelated with $P_{t}$, and therefore collectively add a non-negative amount to the variance of $\tilde{P}_{t}$. Thus, the variance bound is once again

$$
\tilde{P}_{t} \geq P_{t}
$$

Remembering that inequality (9) was derived under the assumption of a rational bubble, it is clear that if the variance bound is violated in data, this cannot be attributed to the presence of a rational bubble.

In general, variance bounds tests are tests of the present value model and rejection (even when there are no econometric problems) may be due to any assumption of the model failing. In a later strand of the variance bounds literature, Campbell and Shiller $(1988,1989)$ provide a log linear approximation to the dividend/price ratio and estimate a vector autoregression system allowing for time-variation in the discount rates. In the absence of a bubble, the dividend/price ratio will be stationary even if dividends and prices have unit roots (more on this in Section 3.3). They find that even when the constant discount factor assumption is relaxed, there is still substantial unexplained variance in the divided/price ratio. They do not, however, make an argument about bubbles.

Cochrane (1992) explicitly tests for a bubble using the variance of the dividend/price ratio. His test, essentially, asks whether there exists a discount rate process that 'explains' the dividend/price volatility. If no discount rate process can generate the observed dividend/price behaviour one may conclude that it must be a bubble that drives prices. Note that the 'standard' model imposes some conditions on the discount rates (the discounted sum of dividends converges and the discount 
rate cannot be negative) so finding a process that justifies the dividend/price ratio process is not trivial. Cochrane finds that there exists a time-varying discount rate process that fits the data (without requiring a bubble), and that this process satisfies the model restrictions while being 'reasonable' in terms of the Hansen-Jagannathan (1991) bound.

\subsection{West's Two-Step Tests}

It is clear from the discussion of the variance bounds tests that testing for the validity of the standard model and bubbles are related but different endeavours. For a 'test of bubbles', a bubble should at least be in the set of alternatives when the test rejects the standard model. A milestone test of equity price bubbles that explicitly put a bubble in the alternative hypothesis was West's (1987) test. This cleverly designed test also tries to tackle the 'simultaneous test of model specification and bubbles' problem by testing the model and no-bubbles hypotheses sequentially.

West's insight was to observe that, in the absence of bubbles, the Euler equation that forms the basis of no-arbitrage asset pricing can be estimated alone, which provides information about the discount rate. Then, if dividends can be represented as an autoregressive (AR) process, knowing the discount rate and the parameters of the AR process that governs dividends provides enough information to pin down the relationship between dividends and the market fundamental stock price. The actual relationship between stock prices and dividends can be directly estimated by regressing the stock prices on dividends. Under the null hypothesis that there are no bubbles, the 'actual' relationship should not differ from the 'constructed' one.

The beauty of this method is that if the two estimates of the impact of dividends on equity prices differ it is possible to trace the discrepancy to model misspecification or bubbles. (A similar idea is employed by Chirinko and Schaller (1996), who propose jointly testing for the Tobin's $Q$ equation and the investment Euler equation. If the model is correctly specified, the $Q$ equation should be informative about equity pricing and bubbles, while the investment Euler equation should show the relationship between asset prices and real investment.) In West's method, the econometrician can apply specification tests to the Euler equation and the AR representation of dividends, ruling out model misspecification and leaving bubbles as the only possible reason for the difference between the two estimates. Thus, this bubble detection method is conceptually very appealing, but it does have problems in implementation. These are discussed within the context of a simple example that West (1987) works out.

The Euler equation derived from the consumer's optimization problem, under the assumptions discussed in Section 2, implies

$$
P_{t}=\left(\frac{1}{1+r}\right) E_{t}\left(P_{t+1}+d_{t+1} \mid \Omega_{t}\right)
$$

which is the same as equation (2) but makes the dependence of the pricing equation on the consumer's information set, $\Omega_{t}$, explicit. Equation (10) can be cast in a 
regression form using observable variables:

$$
P_{t}=\left(\frac{1}{1+r}\right)\left(P_{t+1}+d_{t+1}\right)+u_{t}
$$

where $u_{t}$ is $[1 /(1+r)]\left[E_{t}\left(P_{t+1}+d_{t+1} \mid \Omega_{t}\right)-P_{t+1}+d_{t+1}\right]$. The correlation of the error term with the regressors is bad news for ordinary least squares (OLS) but in this context the past history of dividends are natural candidates for instruments, which West uses. The instrumental variables estimation of (11) provides an estimate of the discount rate. Notice that this inter-temporal relationship between $P_{t}$ and $P_{t+1}$ is independent of the presence of a bubble. It only asserts that there are no arbitrage opportunities, with or without a bubble.

The next step is characterizing the dividend process. Assume for the sake of this example that dividends are exogenous and follow a stationary AR(1) process of the form

$$
d_{t}=\phi d_{t-1}+u_{t}^{d}
$$

The autoregressive parameter is easily recovered by an OLS regression. Given this setup, the market fundamental stock price should be

$$
P_{t}^{f}=\sum_{i=1}^{\infty}\left(\frac{1}{1+r}\right)^{i} E_{t}\left(d_{t+i} \mid \Omega_{t}\right)=\bar{\beta} d_{t}
$$

where

$$
\bar{\beta}=\frac{\phi /(1+r)}{1-\phi /(1+r)}
$$

The actual stock price, on the other hand, may contain a bubble. $P_{t}$ is the sum of the market fundamental price and possibly a bubble component, which the null hypothesis sets to zero. If the null hypothesis is true, estimating the stock price equation

$$
P_{t}=\beta d_{t}+B_{t}
$$

without taking into consideration a bubble (regressing $P_{t}$ on $d_{t}$ ) will provide the 'correct' estimate of $\beta$. If there does exist a bubble in the data, and if the bubble is correlated with dividends, the estimate of $\beta$ in equation (14), $\widehat{\beta}$, will be biased. Note, however, that in this setup $\widehat{\beta}$ will only be biased if the bubble is correlated with dividends and thus the test will 'detect' only this kind of bubble.

West's test exploits being able to estimate $\beta$ in two ways. If the estimated Euler equation in (11) correctly characterizes inter-temporal asset pricing, and an AR dividend process can be estimated, one estimate of the relationship between dividends and market fundamental stock prices is given by $\bar{\beta}$. The second estimate, $\widehat{\beta}$, is expected to be the same as this in the absence of bubbles, but will differ from $\bar{\beta}$ if bubbles are present in the data. Comparing these two estimates is the essence of West's test of speculative bubbles. ${ }^{7}$

Using a Hausman coefficient restriction test West strongly rejects the equality of $\bar{\beta}$ and $\widehat{\beta}$ coefficients, indicating the presence of a bubble. There are numerous 
practical issues that arise in performing this test. The first issue is non-stationarity; West points out that if data are non-stationary the test can be applied to appropriately differenced data. Because detecting non-stationarity with a reasonable degree of certainty is difficult, he runs his tests in levels and in differences. The second issue is determining the order of the AR process that governs dividends, which we took to be 1 in equation (12) for simplicity. Related to this is the issue of information available to agents but not to the econometrician: investors form their expectations about futures dividends taking into account more information than just the history of the dividend process. West's test, in its general form, is designed to handle

$$
P_{t}=\sum_{i=1}^{\infty}\left(\frac{1}{1+r}\right)^{i} E_{t}\left(d_{t+i} \mid \mathcal{F}_{t}\right)+B_{t}+\varepsilon_{t}^{w}
$$

where

$$
\varepsilon_{t}^{w}=\sum_{i=1}^{\infty}\left(\frac{1}{1+r}\right)^{i}\left[E_{t}\left(d_{t+i} \mid \Omega_{t}\right)-E_{t}\left(d_{t+i} \mid \mathcal{F}_{t}\right)\right]
$$

The information set $\mathcal{F}_{t}$ is a subset of $\Omega_{t}$ and includes the past history of dividends. In this case $\varepsilon_{t}^{w}$ is uncorrelated with past dividends, but it will be autocorrelated. West derives coefficient restrictions for this case, where the restrictions are more involved but have the same underlying idea as the AR(1) case discussed above.

The next issue is the choice of econometric method to test model specification and coefficient restrictions. West uses a number of specification tests for the Euler equation and the dividend equation, including structural break tests. His coefficient restriction test, as mentioned above, is a Hausman test that leads to a rejection of the equality of coefficients null hypothesis. Dezbakhsh and Demirguc-Kunt (1990) criticize West's econometric methodology on the grounds that his tests have size distortion in small samples (reject the null too often) and are inconsistent under the bubble alternative. ${ }^{8}$ They propose tests with better small sample properties to check whether $\widehat{\beta}$ is indeed different from $\bar{\beta}$, and find no evidence of bubbles.

The question about the interpretation of rejecting the no-bubbles hypothesis is still valid. As West points out, a rejection may be due to the presence of a bubble, but it may also be due to failure of the model in some other dimension. Indeed, when he allows for time varying discount rates, he finds no evidence of bubbles under the difference stationarity assumption. Although his approach allows for separate testing of model misspecification and bubbles, it is difficult to test for every contingency in terms of model misspecification. For example, West tests for a structural break in mid-sample in his model equations and does not find one; however, if discount rates are time varying but still mean reverting, his test would not detect this, which may explain why his Euler equation passed the specification test but allowing for time varying discount rates made a difference in rejecting the no-bubbles hypothesis.

Flood et al. (1994) point out a related issue. The Euler equation in (11) is derived and tested for two consecutive periods but it should hold in its more general form to price long lived assets. The general form is a relationship between any two periods 
in the future:

$$
P_{t}=\left(\frac{1}{1+r}\right)^{k} P_{t+k}+\sum_{i=1}^{k}\left(\frac{1}{1+r}\right)^{i} d_{t+i}+u_{t}^{k}
$$

where $u_{t}^{k}$ is once again a composite error term, reflecting the difference between expected and actual outcomes. 9 The market fundamentals price, equation (13), relies upon this relationship holding not just for consecutive periods but for periods infinitely apart. Flood et al. argue that, although equation (15) holding for consecutive periods exactly implies that it should hold for any two periods, the statistical error in its estimation may be small for consecutive periods (not leading to a rejection) but may accumulate and be very large for periods further apart. They test equation (15) for $k$ equaling one and two and find that while they replicate West's results for $k=1$, for $k=2$ the specification tests reject equation (15). Notice that this rejection does not point towards arbitrage opportunities or irrationality; it suggests that the risk-neutral agent-constant discount rate Euler equation is not a good approximation to reality.

Flood et al. also point out that even if the model did not have any problems detectable with specification tests, a rejection of the coefficient restrictions may still be due to factors other than a bubble. Their alternative is one that is also suggested by Hamilton and Whiteman (1985) and Flood and Hodrick (1986): agents might attribute a small probability to an event that will have a large impact on the asset price (the so-called peso problem). The standard example of this is a tax law change that agents put a positive probability on and therefore incorporate into stock prices, but the change does not happen in sample. If there are such large impact events that happen very seldom, these events may not be captured even in samples of 100 years of annual data. Expected regime switches, especially those that fail to materialize, pose a major problem for bubble detection because their observed impact on stock prices is similar to that of bubbles.

\subsection{Integration/Cointegration Based Tests}

The tests so far have imposed very little structure on bubbles. Both variance bounds tests and West's two-step tests try to detect 'something other than fundamentals'. West's test would 'find' a bubble by eliminating all other alternatives by appropriate specification tests. Bubbles, however, have certain theoretical properties that may be exploited for their detection.

Diba and Grossman (1987, 1988a) observe that a rational bubble cannot start; thus if it exists now, it must always have existed. The reasoning depends on lack of arbitrage opportunities and impossibility of negative prices. Lack of arbitrage opportunities imply that there are no excess returns from holding an asset with a bubble component, i.e.

$$
E_{t}\left(B_{t+1}\right)=(1+r) B_{t}
$$


as in equation (4). In this case, the actual bubble process (assuming it is a stochastic bubble) follows a stochastic difference equation:

$$
B_{t+1}-(1+r) B_{t}=z_{t+1}
$$

with

$$
E_{t}\left(z_{t+i}\right)=0 \quad \forall i \geq 1
$$

If $B_{t}$ is zero, the bubble will start with the next non-zero realization of $z$. If this realization is a negative number, the bubble will be negative and progressively larger in absolute value in expectation, according to its law of motion. This implies that the stock price will be negative in finite time, which is impossible given free disposal. ${ }^{10}$ If the expected realization of $z$ cannot be negative when the bubble component is zero, it cannot be positive either, because it has to be zero in expectation to rule out arbitrage opportunities. Thus, when $B_{t}$ is zero, all future realizations of $z$ must be zero with probability one, and the bubble cannot (re)start. (This argument, as will be shown later, depends on the implicit assumption that if a bubble 'pops' it must collapse to zero.) Given this argument, Diba and Grossman conclude that, if there is a bubble, it must have existed from the first day of trading. They see this as an argument to rule out rational bubbles, and propose a way to empirically test the absence of bubbles.

Their test for bubbles (1988b) allows for unobserved fundamentals, and imposes some structure on which deviations from fundamentals in data may be blamed on the presence of bubbles. Diba and Grossman specify the market fundamental price to be

$$
P_{t}^{f}=\sum_{i=1}^{\infty}\left(\frac{1}{1+r}\right)^{i} E_{t}\left(d_{t+i}+o_{t}\right)
$$

$o_{t}$ denoting the fundamentals unobservable to the econometrician. ${ }^{11}$ Under the assumption that $o_{t}$ is not more non-stationary than $d_{t}$ (if dividends are stationary when twice differenced, $o_{t}$ is assumed to be stationary when at most twice differenced, for example), the market fundamentals price will be as stationary as the dividends. In the absence of bubbles, if dividends are stationary in levels, stock prices will be equal to market fundamentals and should also be stationary in levels; if dividends are stationary in $n$th differences, stock prices should be stationary in $n$th differences.

This relationship breaks down in the presence of bubbles, which provides an intuitive bubbles test. The $n$th difference of the bubble process, from equation (16), is

$$
(1-L)^{n}[1-(1+r) L] B_{t}=(1-L)^{n} z_{t}
$$

Diba and Grossman note that for standard simple processes for $z$ (such as white noise) the first difference of the bubble is generated by a non-stationary and noninvertible process. Indeed, the bubble process is non-stationary regardless of how many differences are taken and this is a property that can be tested econometrically. Note that it is the argument that the bubble does not pop and restart that makes this 
assertion correct in realized values, and not only in expectation. A process that is unit root in expectation but falls to zero and restarts periodically in realization may have different econometric implications, as will be discussed below.

A natural way to test for the existence of a bubble in the data, then, is to see whether stock prices are stationary when they are differenced the number of times required to make dividends stationary. Diba and Grossman also observe that although both dividends and stock prices are integrated of order one, equation (18) imposes an equilibrium relationship between these two series. Under the null hypothesis of no bubbles in stock prices, and assuming that $o_{t}$ is stationary, dividends and stock prices should be cointegrated. ${ }^{12}$ Note that the assumption made about the unobserved fundamentals is more stringent this time; they should be stationary in levels although dividends only need to be stationary in differences for the test to work.

Using Dickey-Fuller tests, Diba and Grossman find that both dividends and stock prices are integrated in levels, but stationary in differences. Thus, their first test indicates that there are no bubbles. When they test for cointegration using Bharghava (1986) ratios, they also find strong evidence for cointegration of stock prices and dividends. They interpret these findings as indicating that a stock price bubble is not present in the data.

Before moving on to Evans's (1991) criticism of these tests, it is useful to think about the interpretation of the results had they indicated that stock prices are more non-stationary than dividends, or that dividends and stock prices are both I(1) but are not cointegrated. One problem with integration/cointegration based tests is the econometric problems of detecting non-stationarity and estimating cointegrating relationships. This is a problem regardless of the outcome of the bubble tests; there are many competing tests with different size/power properties and these need not agree on the result. In the case that the tests do indicate the presence of a bubble, the correct interpretation is that they suggest the presence of 'something non-stationary' in the (appropriately differenced) stock price. This could of course be because of a bubble, but it can also be that the assumption made on the unobserved fundamentals does not hold, and the $o_{t}$ series is, say, integrated of order two while dividends are I(1). It would of course then be an open question whether one can come up with a reasonable unobserved fundamental that would be I(2). Diba and Grossman also allude to this point and argue that although a rejection of the stationarity/ cointegration conditions would not be proof of a bubble, failing to reject is proof of non-existence of bubbles. Evans (1991) disagrees.

Evans points out that although Diba and Grossman's argument about bubbles only starting on the initial date of trading implies a bubble cannot pop and restart, it is possible that the bubble will collapse to a small non-zero value and then continue increasing, and still follow equation (4). His example of a periodically collapsing bubble is

$$
\begin{array}{ll}
B_{t+1}=(1+r) B_{t} v_{t+1} & \text { if } B_{t} \leq \alpha \\
B_{t+1}=\left\{\delta+\pi^{-1}(1+r) \theta_{t+1}\left[B_{t}-(1+r)^{-1} \delta\right]\right\} v_{t+1} & \text { if } B_{t}>\alpha
\end{array}
$$


where $E_{t} v_{t+1}=1$, and $\theta_{t+1}$ takes the value of 1 with probability $\pi$ and 0 with probability $1-\pi$. This formulation of the bubble satisfies equation (4); the expected gross return from the bubble is always $1+r$. For small values of $B_{t}$ the bubble increases slowly; once it is larger than a threshold value, $\alpha$, it expands faster but may collapse each period with probability $1-\pi$. In the case of a collapse, the bubble's value does not shrink to zero; rather, it becomes a small positive quantity, $\delta$. In this case the bubble is not subject to the Diba and Grossman criticism of restarting because it never 'pops'; it only gets discretely smaller periodically. This example of bubbles exploits the fact that the bubble only has to increase at rate $r$ in expectation, but it may collapse in realization.

Evans generates data from a model with bubbles and does Monte Carlo experiments of the Diba and Grossman bubble detection test, using their specification of a bubble (approximated by setting $\pi$ close to unity). He finds that in this case the test works well, as Diba and Grossman claim. He then uses lower values of $\pi$ so that the bubble periodically collapses. In this case, even for values of $\pi$ as high as 0.95 , the tests perform much worse, failing to reject the no-bubbles hypothesis more often than not. For $\pi$ smaller than 0.75 , the tests almost never detect bubbles.

The unit root based tests have difficulty detecting collapsing bubbles because these behave more like stationary processes than like explosive processes as a result of the periodic collapses involved. This, of course, does not bode well for the Diba and Grossman testing strategy. As noted above, rejecting the no-bubbles hypothesis with these tests may be due to time variation in some other component of the present value model, imparting non-stationarity to differenced stock prices. From Evans's study, it appears that failing to reject the no-bubbles hypothesis with these tests may not be conclusive proof that bubbles are indeed absent from data, either.

It is important to note that Evans does not show the existence of bubbles in stock prices; he only shows that unit root tests are not adequate to reject this hypothesis. ${ }^{13}$ However, we do learn from Diba and Grossman's unit root tests that monotonically increasing bubbles are indeed not in stock prices. We can at least rule out a certain class of bubbles.

Evans's criticism of unit root tests of rational bubbles led to a number of papers trying to overcome the difficulty of detecting collapsing bubbles. The favourite method of attack was to think of expanding and collapsing periods of the bubble as different regimes. This way of modelling the bubble leads to unit root tests where regime shifts in the mean that follow a Markov process are allowed for under the null. ${ }^{14}$

Hall et al. (1999) treat each component of the Evans collapsing bubble (equations (19) and (20)) as a separate regime with constant switching probabilities. Their Monte Carlo experiment shows that Markov switching augmented DickeyFuller tests perform well in detecting bubble episodes, but they do not have an empirical application to stock price bubbles.

Van Norden and Vigfusson (1998) study the regime switching bubbles tests of Hall and Sola (1993) and Van Norden (1996) and conclude that '...even with several hundred observations, the tests show sometimes considerable size distortion'. In 
their application, the Hall and Sola test, which has constant switching probabilities, suggests the existence of bubbles in the S\&P500, but the Van Norden test, which models the switching probabilities as functions of the size of the bubble, does not indicate the presence of a bubble in the same data set. There are many ways to model collapsing bubbles, and Van Norden and Vigfusson's comparison of two of these seems to suggest that the exact choice of the process to be tested does matter.

Markov switching tests of collapsing bubbles allow the bubble to switch between two states, but the fundamentals do not change. Driffill and Sola (1998) provide a striking example of switching fundamentals that match the data equally well in the context of a possible intrinsic bubble, once again demonstrating the lack of identification in bubble testing. Their approach is described at the end of the next section.

\subsection{Intrinsic Bubbles}

Bubbles may or may not be correlated with fundamentals. If they are uncorrelated with fundamentals, they must grow exogenously at an expected rate of $1+r$ per period to be arbitrage free. In this case the bubble and the fundamentals diverge at an explosive rate. Froot and Obstfeld (1991) suggest a different formulation of bubbles, one in which the bubble is tied to the level of dividends. The stock price, fundamental price and bubble processes are once again given by ${ }^{15}$

$$
\begin{gathered}
P_{t}=\frac{1}{1+r} E_{t}\left(D_{t}+P_{t+1}\right) \\
P_{t}^{f}=\sum_{i=1}^{\infty}\left(\frac{1}{1+r}\right)^{i} E_{t}\left(D_{t+i}\right) \\
B_{t}=\frac{1}{1+r} E_{t}\left(B_{t+1}\right)
\end{gathered}
$$

To tie the bubble to fundamentals, dividends should be explicitly modelled. Froot and Obstfeld assume that log dividends, denoted by $d_{t}$, follow a random walk with drift:

$$
d_{t}=\mu+d_{t-1}+\xi_{t}
$$

where $\xi_{t} \sim \mathrm{N}\left(0, \sigma^{2}\right)$. It is easy to verify that a bubble process of the form

$$
B\left(D_{t}\right)=c D_{t}^{\lambda}
$$

where $\lambda$ is the positive root of $\lambda^{2} \sigma^{2} / 2+\lambda \mu-\ln (1+r)=0$ and $c$ is an arbitrary positive constant, satisfies equation (23). ${ }^{16}$ This bubble process depends entirely on the level of dividends, and does not take off on its own. ${ }^{17}$ If such a bubble is present, stock prices will be more sensitive to dividend innovations than is justified by the 
linear pricing equation in (22). Given the law of motion of dividends, and assuming that $D_{t}$ is known at the beginning of the period, the sum in that equation converges to

$$
P_{t}^{f}=\kappa D_{t}
$$

where

$$
\kappa=\frac{\mathrm{e}^{\left(\mu+\sigma^{2} / 2-\ln (1+r)\right)}}{(1+r)-\mathrm{e}^{\left(\mu+\sigma^{2} / 2\right)}}
$$

Under the null hypothesis of no (intrinsic) bubbles, prices are a linear function of dividends and the price/dividend ratio is a constant, $\kappa$, as suggested by equation (26). Intrinsic bubbles impart non-linearity into the relationship between stock prices and dividends. In this case, the price/dividend ratio is

$$
\frac{P_{t}}{D_{t}}=\kappa+c D_{t}^{\lambda-1}+\iota_{t}
$$

where $\iota_{t}$ is a well behaved error term. ${ }^{18}$ The different behaviour of the price/dividend ratio in the absence and presence of bubbles can be exploited to form a bubble test. Froot and Obstfeld test for bubbles by running regressions of price/dividend ratios on a constant and dividends. Not finding any significant coefficients except for the constant in these regressions will indicate lack of bubbles, while finding a nonlinear relationship between prices and dividends will be interpreted as signalling the presence of an intrinsic bubble. In the event, Froot and Obstfeld find strong evidence for positive values of $c$; however, they point out that the results may '. . .merely show that there is a coherent case to be made for bubbles alongside ... alternative possibilities. If that is so, then we should not feel too comfortable about how well we really understand stock prices.' Indeed, their tests show that there exists a non-linear relationship between stock prices and dividends (see also Ma and Kanas (2004) for a test along very similar lines), but this is interpreted as a sign of bubbles only because the model is assumed to be linear. What if the 'true' model is non-linear?

Driffill and Sola (1998) formalize this argument about the underlying stock pricing model being non-linear. They note that the time invariance of Froot and Obstfeld's random walk characterization of the log dividends is central to the analysis and results, and show that this assumption can be rejected when specification tests (in particular, an ARCH specification test) are applied to the data. They propose a regime switching model of dividends:

$$
d_{t}=d_{t-1}+\mu_{0}\left(1-s_{t}\right)+\mu_{1} s_{t}+\left[\sigma_{0}\left(1-s_{t}\right)+\sigma_{1} s_{t}\right] \epsilon_{t}
$$

where $s_{t}$ is a state variable that follows a Markov process with constant transition probabilities. In this case, growth rates of dividends, $\Delta d_{t}$, is distributed $\mathrm{N}\left(\mu_{0}, \sigma_{0}^{2}\right)$ in the $s_{t}=0$ state, and $\mathrm{N}\left(\mu_{1}, \sigma_{1}^{2}\right)$ in the $s_{t}=1$ state. Driffill and Sola verify that this formulation of the dividend process fits the data better, and then test the model with regime switching fundamentals. 
When they include both regime switching fundamentals and intrinsic bubbles, they find that the explanatory contribution of bubbles is low. Their more striking finding is that the fit of a model with regime switches but no bubbles and that of a model with intrinsic bubbles but no regime switches is about the same. The moral of this story is that there is a certain non-linearity in the data that will be attributed to whatever is non-linear in the model.

Van Norden and Schaller (1993, 1999) and Schaller and Van Norden (2002) perform switching regression analyses with more elaborate functional forms of the bubble process, allowing the collapse probability to be linked to the size of the bubble in the expanding bubble regime. In particular, Van Norden and Schaller (1999) take a step towards allowing regime switches in dividends and collapsing bubbles and, like Driffill and Sola, observe that '. . . the model of switching fundamentals is able to reproduce many of the stylized facts of regime-switching found in the data, if not their exact magnitudes' (p. 340).

\subsection{Bubble as an Unobserved Variable}

The econometric bubble detection tests discussed above impose very little structure on the bubble process. Indeed, many of these are tests of the standard model against an unspecified alternative, which is interpreted to be a bubble. These tests do not produce a time series of the bubble component, so it is difficult to evaluate whether the implied properties of the bubble are reasonable or not. Wu (1997) takes the 'bubble as a deviation from the present value model' detection scheme seriously and presents estimated values of the bubble under this interpretation.

His paper specifies the present value model as in Section 2, assuming that differenced dividends follow an AR process (like West), and estimates the bubble as an unobserved variable subject to the no-arbitrage condition using a Kalman filter. He finds that the bubble explains a large proportion of the movement in stock prices; however, Wu's bubble process clearly proxies for the failure of the model in all dimensions. Although the issue is clearest in this paper, this is a general problem of measuring bubbles as a residual. Bubbles will create a residual but any other misspecification of the model will also do so.

\section{Conclusion}

What have we learned from bubble tests? This survey showed that bubble tests do not do a good job of differentiating between misspecified fundamentals and bubbles. This is not only a theoretical concern: for every test of bubbles, there is another paper that disputes the particular 'bubble' interpretation. The finding of a bubble, at best, suggests that the data are consistent with either a bubble or a myriad of other extensions of the standard model. The Driffill and Sola paper highlights this central difficulty of bubble detection perfectly. It is a matter of taste and personal preference that makes the econometrician choose between bubble and fundamentals-based explanations of stock price behaviour. The tests fare somewhat better in detecting a lack of bubbles, but there still are issues about the specification 
of the bubble that is shown not to exist, as pointed out by Evans. The tests are powerful against only certain types of bubbles.

The bubble tests teach us little about whether bubbles really exist or not. However, we do learn valuable stylized facts about the dimensions in which the present value model of stock prices fails. The variance bounds tests, for example, have shown that something is more volatile than assumed in the model. Intrinsic and collapsing bubble arguments highlighted non-linearities that have led to modelling and estimation of regime switching fundamentals. In the end, the underlying model remains a matter of belief. One can as well argue that regime switching fundamentals are a misspecified model that captures the effects of bubbles.

Given these shortcomings of the standard present value model of stock prices, while a strand of the literature is still focusing on theoretically justifying and detecting bubbles, another strand is looking for non-bubble explanations for the apparent anomalies in asset prices, often involving time varying discount rates. For example, Campbell and Cochrane (1999) and the following literature on habit formation essentially make risk aversion a function of consumption and thus cause the discount factor to vary with the business cycle.

In general, having a less restrictive fundamentals model - for example by allowing for time-varying discount rates, risk aversion, or structural breaks - allows the fundamentals part of the model to fit the data better, leaving less room for a bubble. In this sense, the bubble is a catch-all for stock price movements not explained by the model.

We have learned a lot about asset pricing models from bubble detection tests, but we have not learned definitively whether bubbles exist or not.

\section{Notes}

1. The data are from Shiller (2003).

2. This fact is exploited by some of the econometric tests of bubbles that are considered in this survey.

3. LeRoy and Porter's test is essentially a vector autoregression based test of the market fundamental prices, and in this sense is close to the work of Campbell and Shiller (1987, 1988, 1989).

4. Gilles and LeRoy (1991) provide a comprehensive survey of variance bounds tests. Their discussion does not include these tests' applications for bubble detection.

5. His sample is real S\&P500 prices and dividends going back to 1871, at an annual frequency, observed at the beginning of the year. Almost all studies of stock price bubbles in the USA use this data set.

6. Its inapplicability to bubble detection notwithstanding, this paper is a noteworthy attempt to use variance bounds to test the present value model without being subject to earlier criticisms.

7. West (1988a) presents a variance bounds version of this test. The underlying idea is similar, but rather than testing parameter restrictions, the variance bounds version tests a restriction on the variances calculated in two different ways.

8. West also points out the inconsistency of the test when a bubble is present. 
9. $u_{t}^{k}=E_{t}\left[\left(\frac{1}{1+r}\right)^{k} P_{t+k}+\sum_{i=1}^{k}\left(\frac{1}{1+r}\right)^{i} d_{t+i} \mid \Omega_{t}\right]$

$$
-\left(\frac{1}{1+r}\right)^{k} P_{t+k}+\sum_{i=1}^{k}\left(\frac{1}{1+r}\right)^{i} d_{t+i}
$$

10. Tirole (1982) also notes that bubbles must be positive.

11. Diba and Grossman also allow for different valuation of future dividends and capital gains, but this point is not central to the bubble analysis.

12. $P_{t}-(1 / r) d_{t}$ will be stationary if there are no bubbles and the assumption about $o_{t}$ holds. See Fukuta (2001) for a similar test under the assumption that $r$ is time-varying but stationary.

13. Charemza and Deadman (1995) conduct a similar study of bubbles that are stochastic explosive root processes. In this case there are no probabilistic collapses but the AR(1) coefficient in the bubble process (the return on the bubble) is stochastic. They find that unit root tests are unable to detect bubbles in this setup as well.

14. An exception is the work of Taylor and Peel (1998). They propose a cointegration test that is robust to skewness and kurtosis in the error term, which will be the case for a collapsing bubble. In Monte Carlo simulations their test is superior to the Dickey-Fuller test in detecting a periodically collapsing bubble. They do not find evidence of a stock price bubble in the data (1871 to 1987) when they apply their robust test.

In unpublished work $\mathrm{Wu}$ and Xiao (2002) propose a test of collapsing bubbles based on the size of the residuals of the cointegrating relationship. Intuitively, even if periodically collapsing bubbles do not generate unit root residuals, they will still generate large residuals. Wu and Xiao quantify 'large' and base their test on the order of magnitude of the residuals. Their test also does not suggest the presence of bubbles in US stock market data.

15. Froot and Obstfeld define the stock price inclusive of the dividend and $r$ as the instantaneous interest rate which leads to more elegant algebra. Here, the model is recast into an ex-dividends price and $r$ as the period interest rate format to make it comparable to earlier examples of bubble tests.

16. $D_{t}$ has an error term that is log normal, and the expected value of the log normal is a function of its variance, hence the variance terms in evaluating expectations.

17. Testing for a bubble that is correlated with dividends is also the centrepiece of West's test. Froot and Obstfeld impose more structure on the bubble process.

18. The existence of this error term is not well motivated. Froot and Obstfeld suggest it may arise because of within-period predictable excess returns.

\section{References}

Akdeniz, L., Salih, A.A. and Tuluğ, S. Ok. (2006) Variance bounds tests and stock price valuation models revisited. Working Paper, Bilkent University.

Bharghava, A. (1986) On the theory of testing for unit roots in observed time series. Review of Economic Studies 53 (July): 369-384.

Blanchard, O. and Watson, M. (1982) Bubbles, rational expectations, and financial markets. In P. Wachter (ed.), Crises in the Economic and Financial Structure (pp. 295-315). Lexington, MA: Lexington Books.

Camerer, C. (1989) Bubbles and fads in asset prices. Journal of Economic Surveys 3 (February): 3-41. 
Campbell, J. and Cochrane, J. (1999) By force of habit: a consumption-based explanation of aggregate stock market behavior. Journal of Political Economy 107 (April): 205-251.

Campbell, J. and Shiller, R. (1987) Cointegration and tests of present value models. Journal of Political Economy 95 (October): 1062-1088.

Campbell, J. and Shiller, R. (1988) Stock prices, earnings, and expected dividends. Journal of Finance 43 (July): 661-676.

Campbell, J. and Shiller, R. (1989) The dividend-price ratio and expectations of future dividends and discount factors. Review of Financial Studies 1(3): 195-228.

Charemza, W. and Deadman, D. (1995) Speculative bubbles with stochastic explosive roots: the failure of unit root testing. Journal of Empirical Finance 2: 153-163.

Chirinko, R. and Schaller, H. (1996) Bubbles, fundamentals, and investment: a multiple equation testing strategy. Journal of Monetary Economics 38 (August): 47-76.

Cochrane, J. (1992) Explaining the variance of price dividend ratios. Review of Financial Studies 5(2): 243-280.

Dezbakhsh, H. and Demirguc-Kunt, A. (1990) On the presence of speculative bubbles in stock prices. Journal of Financial and Quantitative Analysis 25: 101-112.

Diba, B. and Grossman, H. (1987) On the inception of rational bubbles. Quarterly Journal of Economics 87 (August): 697-700.

Diba, B. and Grossman, H. (1988a) The theory of rational bubbles in stock prices. The Economic Journal 98 (September): 746-754.

Diba, B. and Grossman, H. (1988b) Explosive rational bubbles in stock prices? American Economic Review 78 (June): 520-530.

Driffill, J. and Sola, M. (1998) Intrinsic bubbles and regime switching. Journal of Monetary Economics 42: 357-373.

Evans, G. (1991) Pitfalls in testing for explosive bubbles in asset prices. American Economic Review 31 (September): 922-930.

Flavin, M. (1983) Excess volatility in the financial markets: a reassessment of the empirical evidence. Journal of Political Economy 91 (December): 929-956.

Flood, R. and Hodrick, R. (1986) Asset price volatility, bubbles and process switching. Journal of Finance 41 (September): 831-842.

Flood, R., Hodrick, R. and Kaplan, P. (1994) An evaluation of recent evidence on stock price bubbles. In R. Flood and P. Garber (eds), Speculative Bubbles, Speculative Attacks, and Policy Switching (pp. 105-133). Cambridge, MA: MIT Press.

Froot, K. and Obstfeld, M. (1991) Intrinsic bubbles: the case of stock prices. American Economic Review 81 (December): 1189-1214.

Fukuta, Y. (2002) A test for rational bubbles in stock prices. Empirical Economics 27: $587-600$.

Gilles, C. and LeRoy, S. (1991) Econometric aspects of the variance-bounds tests: a survey. Review of Financial Studies 4(4): 753-791.

Grossman, S. and Shiller, R. (1981) The determinants of the variability of stock market prices. American Economic Review 71 (May): 222-227.

Hall, S. and Sola, M. (1993) Testing for collapsing bubbles: an endogenous switching ADF test. Discussion Paper 15-93, London Business School.

Hall, S., Psaradakis, Z. and Sola, M. (1999) Detecting periodically collapsing bubbles: a Markov-switching unit root test. Journal of Applied Econometrics 14: 143-154.

Hamilton, J. (1986) On testing for self-fulfilling speculative price bubbles. International Economic Review 27: 545-552.

Hamilton, J. and Whiteman, C. (1985) The observable implications of self-fulfilling expectations. Journal of Monetary Economics 16 (November): 353-373.

Hansen, L. P. and Jagannathan, R. (1991) Implications of security market data for models of dynamic economies. Journal of Political Economy 99 (April): 225-262.

Kleidon, A. (1986) Variance bounds tests and stock price valuation models. Journal of Political Economy 94 (October): 953-1001. 
LeRoy, S. and Porter, R. (1981) The present-value relation: tests based on implied variance bounds. Econometrica 49 (May): 555-574.

Ma, Y. and Kanas, A. (2004) Intrinsic bubbles revisited: evidence from nonlinear cointegration and forecasting. Journal of Forecasting 23 (July): 237-250.

Mankiw, N. G., Romer, D. and Shapiro, M. (1985) An unbiased reexamination of stock market volatility. Journal of Finance 40 (July): 677-687.

Marsh, T. and Merton, R. (1983) Dividend variability and variance bounds tests for the rationality of stock market prices. American Economic Review 76 (June): 483-498.

Mishkin, F. and White, E. (2002) U.S. stock market crashes and their aftermath: implications for monetary policy. NBER Working Paper No. 8992.

Schaller, H. and Van Norden, S. (2002) Fads or bubbles? Empirical Economics 27: 335362.

Shiller, R. (1981) Do stock prices move too much to be justified by subsequent changes in dividends? American Economic Review 71 (June): 421-436.

Shiller, R. (1988) The probability of gross violations of a present value variance inequality. Journal of Political Economy 96 (October): 1089-1092.

Shiller, R. (1999) Measuring bubble expectations and investor confidence. NBER Working Paper No. 7008.

Shiller, R. (2000) Irrational Exuberance. Princeton, NJ: Princeton University Press.

Shiller, R. (2003) From efficient markets hypothesis to behavioral finance. Journal of Economic Perspectives 17 (Winter): 83-104.

Taylor, M. and Peel, D. (1998) Periodically collapsing stock price bubbles: a robust test. Economics Letters 61: 221-228.

Tirole, J. (1982) On the possibility of speculation under rational expectations. Econometrica 50: $1163-1182$.

Tirole, J. (1985) Asset bubbles and overlapping generations. Econometrica 53: 1499-1528.

Van Norden, S. (1996) Regime switching as a test for exchange rate bubbles. Journal of Applied Econometrics 11 (July): 219-251.

Van Norden, S. and Schaller, H. (1993) The predictability of stock market regime: evidence from the Toronto stock exchange. Review of Economics and Statistics 75 (August): 505-510.

Van Norden, S. and Schaller, H. (1999) Speculative behavior, regime-switching, and stock market crashes. In P. Rothman (ed.), Nonlinear Time Series Analysis of Economic and Financial Data (pp. 321-356). London: Springer.

Van Norden, S. and Vigfusson, R. (1998) Avoiding the pitfalls: can regime-switching tests reliably detect bubbles? Studies in Nonlinear Dynamics and Econometrics 3: 1-22.

Vissing-Jorgensen, A. (2004) Perspectives on behavioural finance: does irrationality disappear with wealth? Evidence from expectations and actions. Working Paper, Northwestern University.

West, K. (1987) A specification test for speculative bubbles. Quarterly Journal of Economics 102 (August): 553-580.

West, K. (1988a) Dividend innovations and stock price volatility. Econometrica 56 (January): 37-61.

West, K. (1988b) Bubbles, fads and stock price volatility tests: a partial evaluation. Journal of Finance 43: 639-656.

Wu, G. and Xiao, Z. (2002) Are there speculative bubbles in stock markets? Evidence from an alternative approach. Working Paper, Michigan Business School.

$\mathrm{Wu}, \mathrm{Y}$. (1997) Rational bubbles in the stock market: accounting for the U.S. stock-price volatility. Economic Inquiry 35 (April): 309-319. 